\title{
Scientific Literacy: To days Necessity
}

\author{
A Comparative Study of 10th Class Students from Different Schools \\ Dr. Pratima Mishra
}

\author{
Asst. Professor, Dr. D. Y. Patil College of Education, Maharashtra, India \\ Received: 29 Nov 2021; Received in revised form: 10 Jan 2022; Accepted: 23 Jan 2022 \\ (C)2022 The Author(s). Published by TheShillonga. This is an open access article under the CC BY license \\ (https://creativecommons.org/licenses/by/4.0/)
}

\begin{abstract}
This era of the 21st century has been termed as the digital age because in this era the changes taking place in the living conditions of human beings have been such that the digital society has been born. The pace of developmental change in this digital society is so fast that keeping pace with it is a challenging task. In this digital world scientific literacy is very important factor.. In this research we found that urban students are leading in the comparison of rural students and girls are moving faster than boys. It is required to improve scientific literacy in rural area and hurdle is lack of supply of electricity and unavailability of resources.
\end{abstract}

Keywords-Scientific literacy, Digital age and Scientific Literacy Scale

\section{INTRODUCTION}

The era of the new millennium world has started with some such miraculous devices that put the whole world in a small box and give it in our hands. How to work and handle with this is still a question. Now this is our duty to literate our student for this changing world. India is still struggling with Literacy and we are talking about scientific literacy. But what can we do now this is high time to take scientific literacy rate seriously. During the Pandemic of COVID-19 only those peoples, parents and students were not suffered whose scientific literacy and knowledge were high especially about digital knowledge and use of this for the benefit of our own daily problems during pandemic.

\section{"Moto of Digital World Whole World in the Hands of Man”}

The name of this era is "Digital Age" and perhaps by the time of this era, we can also say that now the control of the entire space is in our hands. But this Amazing development has not happened in a day or two, but to reach this position, man has to show hard work and indomitable courage and is show hard work and indomitable courage till now. To understand this digital age, understanding of science and technology is necessary so that by developing decision-making ability, students can present their right participation in front of the digital society.

\section{Concept of Scientific Literacy:}

Scientific literacy literally means having knowledge of the basic sources of science but broadly looking at the basic understanding of the nature of science in which science is not related as an independent subject but is related to society and its needs, aspirations and social aspects, scientific literacy It is called

\section{Justification of Study:}

This era of the 21 st century has been termed as the digital age because in this era the changes taking place in the living conditions of human beings have been such that the digital society has been born. The pace of developmental change in this digital society is so fast that keeping pace with it is a challenging task.

The present digital age is not only the era of Explosion of Knowledge, but in this era two more explosions are taking place in the WORLD and it is the, Explosion of Aspiration and Explosion of Population.

\section{Three Challenges of Digital Age:}

I. Explosion of Population India

II. Explosion of Knowledge

III. Explosion of Aspiration

It is a difficult task to make oneself alive in the digital age, while satisfying the hunger of scientific and technical knowledge while raising oneself in the danger of these explosions. A student of secondary level, who is a future citizen of the country, has such a level of scientific literacy 
that he will be able to fulfill his responsibility towards the country and society by taking care of himself in this era. It is important to know the answer to this question. Thus by ascertaining the level of scientific literacy, it can be concluded that Maybe what kind of saplings are we preparing for the digital society, are there any objectives, curriculum, process and need of education in this context? Title of Research Improved Evaluation Context

\section{Statement of the Problem:}

In National Curriculum Framework 2000 (pages 5658 ), it is found that considering science as an important subject, it has been given a place in the secondary level curriculum, whose main objective is to understand science and its basic principles and rules. Information has been given to the students, that is, to bring scientific literacy among the students, the aim of the secondary level science curriculum is. Therefore, to find out the scientific literacy of students at this stage, the researcher has taken this research work, which is titled:

Scientific Literacy: A Comparative Study of 10th Class Students from Different Schools

\section{Objectives:}

1. Comparison of achievements of urban government, rural government and public school students with reference to the "nature of science" in the first dimension of scientific literacy.

2 .The second dimension of scientific literacy is to compare the achievement of urban government, rural government and public school students in the context of "value of science".

3. In the context of "Third Dimension Society of Scientific Literacy", "Science and achievement of students of urban government, rural government and public schools to compare in.

4. The fourth dimension of scientific literacy is to compare the achievement of urban government, rural government and public school students in the context of "science related to social issues".

5. Total students with reference to the dimension "nature of science and to compare the scientific literacy of girl students.

3. To compare the level of scientific literacy of all boys and girls with reference to the dimension "Values of Science".

4. To compare the level of scientific literacy of all boys and girls with reference to the dimension "Science and Society".
5. To compare the level of scientific literacy of all boys and girls with reference to the dimension "Science related to social issues".

\section{Research Hypothesis:}

1. First Dimension of Scientific Literacy "With respect to the nature of science, there is no significant difference between the students of urban government, rural government and public schools.

2. There is no significant difference between urban government, rural government and public school students in terms of "value of science", the second dimension of scientific literacy.

3. There is no significant difference between urban government, rural government and public school students in the context of "science and society", the third dimension of scientific literacy.

4. There is no significant difference between urban government, rural government and public school students with respect to the fourth dimension of scientific literacy "science related to social issues".

5. There is no significant difference between total boys and girls' scientific literacy with respect to the "nature of science" dimension.

6. All students with reference to the dimension "Values of Science "There is no difference between the scientific literacy of girl students and There is no meaningful difference.

7. There is no significant difference between the scientific literacy of all boys and girls with respect to the dimension "Science and Society".

8. There is no significant difference between the scientific literacy of all boys and girls with respect to the dimension "Science related to social issues"

\section{Defining the Terms:}

1. Scientific Literacy: With the help of principles, scientific facts, concepts and scientific processes, a person develops his own decision-making ability and understands, whose current perspective enables him to lead a successful life, and it is called scientific literacy. Scientific literacy provides a living experience to the individual; its level depends on the need of time, place and society.

2. Scientific Literacy Scale: Tool in which the scientific literacy known sentence is divided into four dimensions Nature of Science, Values of Science, Science and Science related to society and social problems. The level of scientific literacy can be ascertained by this tool. 


\section{Limitations of Research:}

Keeping in mind the physical and human resources available in the college, research work was limited and time was also taken care of, which is as follows:

1. The research was done in all its four dimensions based on a single dependent variable scientific literacy.

2. Research work was confined to Ajmer district and for the collection of data Government Urban, Rural and public schools were selected.

3. Keeping in view the time and duration, instead of preparing research equipment, already prepared research equipment was used.

4. The sample was kept around 150-160 so that the collection and analysis can be done easily.

\section{Selection of Sample:}

As a sample the researcher select 166 students studying in class 10 of different schools of Ajmer district by random sampling technique.

\section{Research Tool:}

For the research work, the researcher used the scientific literacy scale as a tool to compile the data provided by Dr. MK Sharma. In this scale, there are a total of 25 statements related to four dimensions. In this scale, all the students have to read the statements and give their decision on a five point scale. While giving marks to the answers obtained from, the researcher can be obtained by counting the answers by giving 01, 2, 3, 4 marks keeping in mind the terms having positive polarity and negative polarity.

\section{Type of research:}

This research comes under the category of descriptive survey.

\section{Variables:}

The type of schools and gender have been taken as independent variables in this research, while the dimensions of measuring scientific literacy are taken as dependent variables, their details are as follows:

Independent variables

(a) Types of school Urban/ rural Government School and Public school

(b) Boys/girls

Dependent Variables: Four Dimensions of Scientific Literacy
(A) Nature of Science
(B) Values of Science
(c) Science and Society
(d) Science dealing with social issues

\section{Statistics Used in Research:}

In this research researcher used, mean (M) standard deviation (SD), $t$ value $(\mathrm{t})$ and ANOVA for the analysis of data. The Bon ferine Multiple Comparison Post HOC Test were used to make mutually exclusive comparisons of multiple variables. The entire analysis work was done through computer.

\section{CONCLUSIONS}

In terms of the "nature of science" dimension, scientific literacy is highest among urban government school students while the lowest among public school students.

2. Scientific literacy in terms of "value of science" dimension was found to be highest among public school students while lowest among rural government school students.

3. No significant difference was found between public school, urban government school and rural government school students in the level of scientific literacy with respect to the "science and society" dimension.

4. Scientific literacy in terms of the dimension "Science related to social issues" was found to be highest among public school students while it has been the lowest for urban government school students

5. No significant difference found in scientific literacy of boys and girls with respect to the dimension "nature of science"

6. No significant difference found in scientific literacy of boys and girls with respect to the dimension "values of science"

7. No significant difference was found in the scientific literacy of boys and girls with respect to the dimension "science and society".

8. Scientific literacy of girl students is higher than that of boys in terms of "science related to social issues" dimension.

\section{EDUCATIONAL IMPLICATIONS OF RESEARCH}

Research work is completed only when its usefulness otherwise it would be a futile exercise. Some points emerge from the experiences and conclusions obtained during this research, which can be used practically:

1. Curriculum should be improved to increase the scientific literacy of the students at the secondary level. 
2. Teachers should make special efforts at the time of teaching for the development of scientific literacy in general.

3. Teachers should always try to develop their own scientific literacy.

4. Scientific Activities should included in science textbook so that it is mandatory for the students to use them to develop scientific literacy.

5. The school environment has a great influence on students so to improve the level of scientific literacy the school environment needs to adapt activities based on scientific literacy.

6. From the point of view of general knowledge of the scientific changes taking place in the society, students should be involved in the teaching-learning process.

7. In order to satisfy the curiosity and knowledge craving of the students, the teacher should cooperate; it is unfair to put them under unnecessarily pressure.

8. Activities in schools for the development of scientific co-scholastic literacy like Science Quiz, essay reading, debate, speech competition etc. should be organized.

9. For the development of scientific literacy among the students, concepts, rules and formulas of science should be linked with ordinary life.

10. Science fair, science Exhibitions, Environmental friendly science programs, documentaries are good idea for the development of scientific literacy.

Suggestions for future research:

On the basis of the present research, it was considered necessary that the researcher should make the future researchers aware of their experiences doing research related to science education. This will help them in formulating and working on research problems. Following are the problems for future research:

1. Study of scientific literacy of students at upper primary and primary level.

2. To compare the scientific literacy of science teachers and other teachers.

3. To find out events and activities that lead to the development of scientific literacy is a part of further research

4. Analytical study can be carried out on text books that which contents develop scientific literacy and which content needs modification.

5. To compare the scientific literacy of students of science subjects with students of other subjects at senior higher secondary level.
6. Compare the personality characteristics of students with their level of scientific literacy.

7. To compare the level of scientific literacy of students with the level of scientific literacy of their teachers.

8. Explain the role of co-scholastic activities in the context of development of the level scientific literacy of students.

9. To study the role of media in the development of scientific literacy can be carried out.

10. Comparative Study of scientific literacy with the level of Confidence is a good subject of study.

11. Role of School Environment in Development of Scientific Literacy case study can be done

\section{REFERENCES}

[1] Sharma M.K.: A Study Of Scientific Literacy, Attitufde Towards Science And Pessonality Trails Of Students And Teachers Ph.D. Thesis RIE, Ajmer (1989)

[2] Richard Carrier's: Test You Scientific Literacy (2001)

[3] IAEA Newsletter: Scientific Literacy And Minimun Science Indian Adult Aducation Association New Delhi Vol. 24, No.8 Nov. 2001

[4] BUCH M.B.: Third Survey Of Research In Educatin (1978)

[5] BUCH M.B.: Fourth Survey Of Research In Educatin Vol. I \& II(1983-88)

[6] BUCH M.B.: Fifth Survey Of Research In Educatin Vol. I \& II (1988-92)

[7] Dr. Sood J.K.: New Directions In Science Teaching Kohil Publications Chandigarh (1989)

[8] Nanda V.K.: Science Education Today, Anmol Publications Pvt. Ltd., New Delhi 11002 (India) (1997)

[9] Narendra Vidya : Science Teaching for the 21st Century by Marin Drugeri Deep \& Deep Publication, F-159, Rajouri Garden, New Eelhi 110027 (1996) 